\title{
ANALYSIS OF CO-OCCURRENCE OF AUTISM SPECTRUM DISORDER WITH OTHER NEUROLOGICAL DISORDERS
}

\author{
ELUMALAI CHANDRAKALA, KAKANAHALLI NAGARAJ*
}

Molecular Genetics Laboratory, Department of Applied Zoology, Kuvempu University, Jnana Sahyadri, Shankaraghatta, Shivamogga, Karnataka, India. Email: knagarajv@gmail.com

Received: 13 January 2020, Revised and Accepted: 09 March 2020

\section{ABSTRACT}

Objective: The present study explores the co-occurrence of autism spectrum disorder (ASD) with associated disorders such as epilepsy, attention deficit hyperactive disorder (ADHD), Down's syndrome (DS), and cerebral palsy (CP).

Methods: This cross-sectional study was carried out in special schools of four districts in Karnataka. A total of 49 ASD individuals were identified among 552 developmentally challenged children. ASD individuals were screened for associated neurological disorders and segregated the data as ASD, ASD with epilepsy, ASD-epilepsy-ADHD, ASD with DS, and ASD with CP. The karyotype analysis was carried out for chromosomal anomalies.

Results: It is found that $57 \%$ of the individuals showed only ASD features and the remaining $43 \%$ shared ASD features with other neurological disorders. Among 43\% of comorbidity, 35\% of ASD individuals have epilepsy, $2 \%$ have epilepsy-ADHD, 4\% have DS, and 2\% have CP.

Conclusion: This study supports the strong association between ASD with epilepsy, DS, ADHD, and CP. However, the extent of association of ASD with epilepsy is higher than other neurological disorders. As both are complex neurological disorders, they both show intellectual disability and involve multiple genetic factors. The present investigation is the unique and first report of this study region and also supports earlier studies, suggesting that there is an association of ASD with other neurological disorders.

Keywords: Autism spectrum disorder, Epilepsy, Attention deficit hyperactive disorder, Down's syndrome, Cerebral palsy, Co-occurrence.

(c) 2020 The Authors. Published by Innovare Academic Sciences Pvt Ltd. This is an open access article under the CC BY license (http://creativecommons. org/licenses/by/4. 0/) DOI: http://dx.doi.org/10.22159/ajpcr.2020.v13i5.37025

\section{INTRODUCTION}

Autism spectrum disorder (ASD) is a group of developmental impairments in communication, social interaction, and stereotyped behaviors. ASD children prefer their own world, do not like to mingle with the age-appropriate children. Most of the ASD children look normal and invest their time alone in frightening behavior. About 1\% of the world's population are estimated to be affected by ASD $[1,2]$. The typical ASD has been found to be associated with phenotypes of other known etiologies in 10-25\% of cases, including disorders such as cognitive impairment, Fragile $\mathrm{X}$ syndrome [3-8], Rett syndrome [4], Down's syndrome (DS), neurofibromatosis and tuberous sclerosis $[6,7]$, Epilepsy [9], attention deficit hyperactive disorder (ADHD) [10,11], and cerebral palsy (CP) [12]. All these earlier studies suggest that many neurological disorders are associated with ASD.

Epilepsy is one of the most common neurological disorders in which brain activities become abnormal and earlier it is estimated to have affected 70 million individuals in the world [13]. Both ASD and epilepsy have been affected by many genes. Similar to ASD, epilepsy is also a spectrum condition in which 977 genes have been reported to be associated [14]. Autism databases revealed that around 837 genes are found to be associated with ASD (https://gene.sfari.org/). Association of ASD with epilepsy is fascinating and remains conundrum and this may be due to the involvement of multiple genes in both. The metaanalysis studies on ASD and epilepsy have been tackled by many researchers. An earlier study [15] reveals that both ASD and epilepsy are neurological disorders and exhibit with intellectual disability (ID). It also suggested that the prevalence of epilepsy varies by the degree of ID. ASD occurs 3 times more in males than that of females and the age of onset is early infancy. Whereas, epilepsy can occur in anyone at any time irrespective of gender and age. A study carried out in Denmark found a positive predictive value for epilepsy of $81 \%$ [16].
ADHD is one of the neurodevelopmental disorders with a prevalence of $5 \%$ worldwide [17]. It is associated with many neurological disorders in various proportions. It has been reported earlier that about $30-50 \%$ of ASD [18] and 30\% of epilepsy [19] have been found to be associated with ADHD. All these three conditions (ASD-epilepsy-ADHD) together make a strong association and more complex.

DS is the most commonly found birth defect caused due to 21 trisomy which occurs 1 in 400-1500 live births [20]. Earlier reports suggest that DS and ASD co-occur with each other [7,21]. Similarly, CP is also one of the neurological motor disabilities that occurs 2 in 1000 live births [22] and it co-occurs with ASD at 8\% [12]. The present study describes the comorbidity of ASD and associated disorders. There were no earlier studies reported yet in this region. Further, this study helps to know the relationship between ASD, epilepsy, ADHD, DS, and CP.

\section{METHODS}

The present study was approved by the Institutional Ethical Committee (registration number KU/IEC/05-10/2014-15). This study was carried out in four districts such as Shivamogga, Chikmagalur, Davangere, and Haveri of Karnataka. A total of 552 developmentally challenged children were screened for ASD by following the criteria set in the Diagnostic and statistical manual of mental disorder-IV. The parents/caretakers of ASD individuals were also interviewed, and keen observation was made to screen the behavior of each ASD individual. Along with this, a detailed medical report of ASD individuals obtained from doctors was scrutinized for developmental regression and other associated clinical conditions such as epilepsy, ADHD, DS, and CP

\section{RESULTS}

A significant number of 49 individuals with ASD were identified from the pool of special schools. It reveals that the males (71.43\%) have been 
affected with ASD by two and a half (2.5 times) fold higher than females $(28.57 \%)$

\section{Comorbidity of associated disorders with ASD}

ASD is associated with many neurological disorders, with varying degrees of severity. All the individuals with ASD were showing a different kind of clinical conditions. Among 49 ASD patients, 42.85\% of them showed an association with other medical conditions. In the present study, four different associations (Fig. 1) were observed such as (1) ASD with epilepsy (35\%), (2) ASD with epilepsy-ADHD (2\%), (3) ASD with DS (4\%), and (4) ASD with CP (2\%).

\section{ASD with epilepsy}

In this study, 18 individuals showed an association with epilepsy. One among them showed the clinical features of ADHD. Moreover, the severity of endophenotype was varied in these individuals. Most of them were in the age group of 11-15 years (Table 1)

\section{ASD-epilepsy-ADHD}

One male child among 49 ASD individuals was found to exhibit symptoms of both epilepsy and ADHD. In dispersion through all the other associations, this boy exhibited a higher degree of severity. In this case, the severity may be due to a combination of two medical conditions along with ASD, as both epilepsy and ASD involve multiple genes. Due to the comorbidity of three clinical conditions (ASD+epilepsy+ADHD) in that individual, the severity was so high due to which the boy died at the age of 14 years. The ASD severity scoring has been given from 1 to 4 (i.e., absent to high severity) as represented in Fig. 2.

\section{ASD with DS}

Two of the male ASD individuals have shown the association with DS as revealed by karyotypic analysis, and both the individuals had 21 trisomy. In both cases, the parents were consanguineously married and both ASD individuals showed stereotyped motor mannerism, difficulty in modulating behavior, lack of socialness, autistic withdrawal (preferred to be alone), sensory impairments, echolalia, and speech impairment (Table 2).

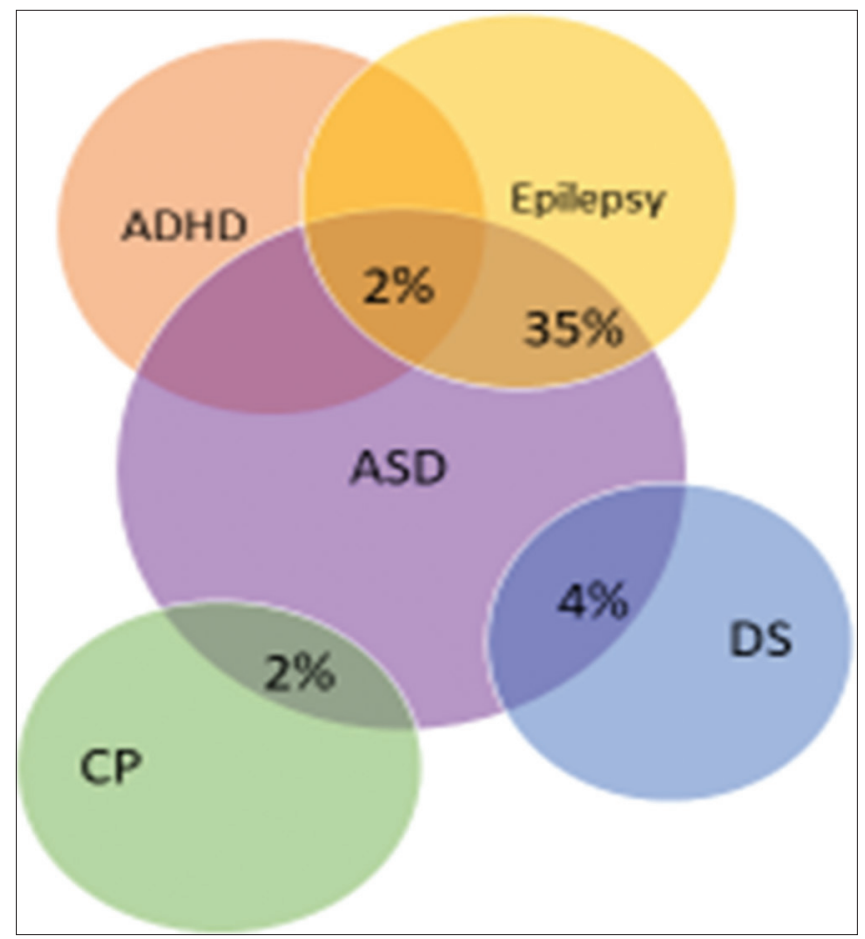

Fig. 1: Representation of autism spectrum disorder and association of other clinical conditions
ASD with CP

Among 49 autistic individuals, one female individual has shown to have CP. All the autistic endophenotypes such as impairments in motor, behavior, sensory, physical, social, and speech were observed in this individual. The clinical examination has reported that during infancy, the child did not show proper development and her neck had got fixed at the age of 6 years.

\section{DISCUSSION}

Most of the neurological disorders show association with each other and this can affect the children qualitatively and quantitatively. In the earlier study, about $35-50 \%$ of the psychiatric children show

Table 1: Description of autism spectrum disorder patients with epilepsy

\begin{tabular}{ll}
\hline Total no. of patients (\%) & 77.78 \\
No. of males & 22.22 \\
No. of females & \\
Age during the study (years) & 2 \\
$0-5$ & 3 \\
$6-10$ & 9 \\
$11-15$ & 4 \\
$16-20$ & \\
\hline
\end{tabular}

Table 2: List of endophenotypic impairments observed between two autistic individuals with down's syndrome

\begin{tabular}{lll}
\hline Autistic endophenotypes & Case 1 & Case 2 \\
\hline Toe walk & + & - \\
Preoccupation to object & - & + \\
Stereotyped motor mannerism & + & + \\
Attachment to object & - & + \\
Auditory withdrawal & - & + \\
Visual attending & + & + \\
Autistic withdrawal & + & + \\
Not toilet trained & + & - \\
Sleep disturbance & + & - \\
Smelling objects & - & + \\
Lack of peer relation & + & + \\
Speech impairment & + & + \\
Lack of multiple non-verbal behaviors & + & + \\
Deficit in social communication & + & + \\
\hline
\end{tabular}

+ : Indicates the presence of autistic endophenotypes. -: Indicates the absence of autistic endophenotypes

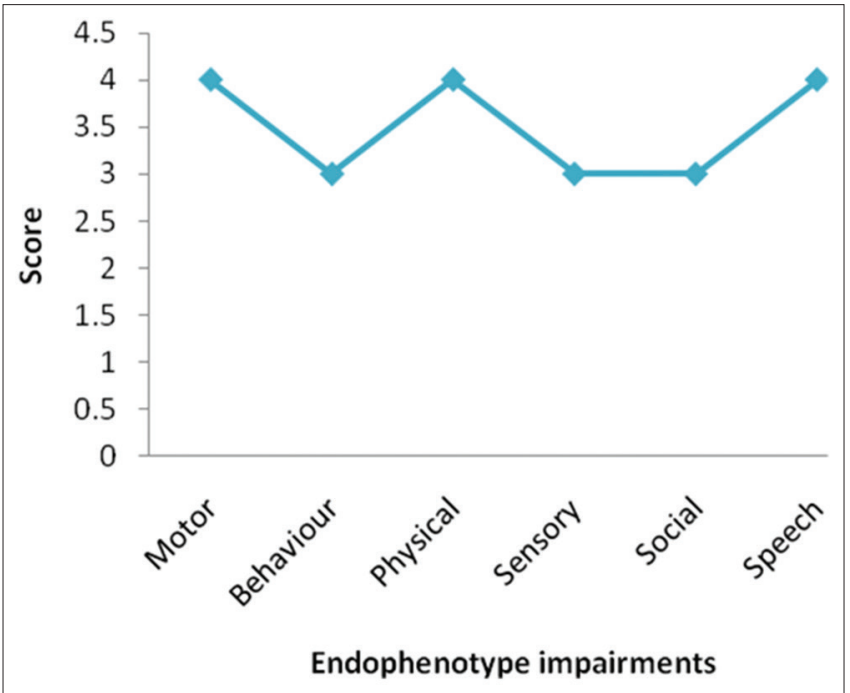

Fig. 2: Autistic endophenotype impairment in an individual with "autism spectrum disorder-epilepsy-attention deficit hyperactive disorder" 
comorbidity with epilepsy [23]. Due to the comorbidity of neurological conditions, it is difficult to treat the children. In the present study, comorbidity of ASD with other neurological disorders was recorded. Of 49 autistic individuals, 21 (42.85\%) of these children have shown an association with other medical conditions such as epilepsy, DS, ADHD, and CP. The severity of autism varies from one individual to another due to variation in the expression of autistic endophenotypes [24]. It also depends on associated parameters such as psychopathology, genetic etiology, and other factors [25]. In addition, it has been reported that oxidative stress can also initiate different neurological disorders [26].

ASD and epilepsy are neurological disorders and in both cases, ID is found to be a major risk factor. It is very difficult to identify whether ASD is caused due to epilepsy or epilepsy is caused due to ASD. Several meta-analysis studies described that the rate of epilepsy in ASD individuals ranges from 6 to $27 \%$ and it is more common [9,27]. However, in our study, the range of association is reported to be $36.73 \%$. A study in Denmark found a positive predictive value for epilepsy of about 81\% [16]. Cross verification of the earlier study [14] and autism database (https://gene.sfari.org/) has revealed that there are 166 genes that are common in both ASD and epilepsy.

Further, in one of the patients, the severity was high due to the comorbidity of two conditions with ASD such as ADHD and epilepsy, and this made the individual to die at the age of 14 years. All these three neurological disorders interfere with the functioning or development and contributing to the ASD to become more complex. Therefore, pathologically, these conditions are interlinked due to which the individual was severely affected. This is a case that provides a shred of evidence for the strong association of ASD with epilepsy-ADHD and this is supported by an earlier study [27].

DS is a genetic disorder and most common autosomal chromosomal trisomy (21 chromosome) resulting in physical and mental deterioration. In the present study, $4 \%$ of cases showed an association with DS. An earlier study [21] suggests that about $1-11 \%$ of comorbidity of ASD and DS was observed.

CP is the most common motor disability and occurs from 1.5 to $4 / 1000$ live births [12]. The present study shows $2 \%$ of children with CP had ASD and both share similar symptoms. However, an in-depth study is necessary to understand the association between ASD and CP.

The results of the present study are suggestive that, when causal factors are more, it makes the understanding of diseases more complex. Hence, it is required to carry out further research to understand the ASD and other associated disorders by studying the several candidate genes involved in these disorders. As a result, we will be able to know the molecular mechanism and processes involved in the etiology of ASD.

\section{CONCLUSION}

The present study reveals the significant association of ASD with neurological disorders. The study further revealed that among all the associated disorders, epilepsy is most noticeable with ASD. Even though the sample size is small, the results obtained were prominent which is unique and the first report of this study region.

\section{ACKNOWLEDGMENT}

We are grateful to all the study participants (autistic children), their parents, and caretakers. We also thank the management of special schools for allowing us to carry out this work.

\section{AUTHORS' CONTRIBUTIONS}

The study was designed and conceptualized by Dr. Nagaraj. He supervised each step of the work, criticized the manuscript, and interpretations of the results. Ms. Chandrakala collected the data of
ASD patients in the study area. She analyzed, interpreted the data, and prepared the manuscript. Both the authors read and approved the final manuscript.

\section{CONFLICTS OF INTEREST}

There are no conflicts of interest among the authors.

\section{FUNDING}

We are thankful to the Science and Engineering Research Board, Department of Science and Technology (DST-SERB), Government of India, New Delhi, for supporting financially.

\section{REFERENCES}

1. Rubies SD, Buxbaum JD. Recent advances in the genetics of autism spectrum disorder. Curr Neurol Neurosci Rep 2015;15:1-9.

2. Fombonne E, Marcin C, Manero AC, Bruno R, Diaz C, Villalobos M, et al. Prevalence of autism spectrum disorders in Guanajuato, Mexico: The Leon survey. J Autism Dev Disord 2016;46:1669-85.

3. Jiang YH, Yuen RK, Jin X, Wang M, Chen N, Wu X, et al. Detection of clinical relevant genetic variants in autism spectrum disorder by wholegenome sequencing. Am J Hum Genet 2013;93:1-15.

4. Wall DP, Esteban FJ, DeLuca TF, Huyck M, Monaghan T, Medizabal NV, et al. Comparative analysis of neurological disorders focuses genomewide search for autism genes. Genomics 2009;93:120-9.

5. Wang XZ, Hou M, Zhang D, Zhong N. Molecular screening of FMR1 mutation among autism patients in China. World J Pediatr 2006;2:285-7.

6. Barnby G, Abbott A, Sykes N, Morris A, Weeks DE, Mott R, et al. Candidate-gene screening and association analysis at the autismsusceptibility locus on chromosome 16p: Evidence of association at GRIN2A and ABAT. Am J Hum Genet 2005;76:950-66.

7. Ruble L, Gallagher T. Autism Spectrum Disorders: Primer for Parents and Educators. Bethesda: National Association of School Psychologists; 2004.

8. Pickles A, Starr E, Kazak S, Bolton P, Papanikolaou K, Bailey A, et al. Variable expression of the autism broader phenotype: Findings from extended pedigrees. J Child Psychol Psychiatry 2000;41:491-502.

9. Jeste SS, Tuchman R. Autism spectrum disorder and epilepsy: Two sides of the same coin? J Child Neurol 2015:30:1963-71.

10. Groom MJ, Kochhar P, Hamilton A, Liddle EB, Simeou M, Hollis C. A typical processing of gaze cues and faces explains comorbidity between autism spectrum disorder (ASD) and attention deficit/hyperactivity disorder (ADHD). J Autism Dev Disord 2017;47:1496-509.

11. Nylander L, Holmqvist M, Gustafson L, Gillberg C. Attention-deficit/ hyperactivity disorder (ADHD) and autism spectrum disorder (ASD) in adult psychiatry. A 20-year register study. Nord J Psychiatry 2012;67:344-50.

12. Kirby RS, Wingate MS, Braun KV, Doenberg NS, Arneson CL, Benedict RE, et al. Prevalence and functioning of children with cerebral palsy in four areas of the United States in 2006: A report from the autism and developmental disabilities monitoring network. Res Dev Disabil 2011;32:462-9.

13. Tang F, Hartz AM, Bauer B. Drug-resistance epilepsy: Multiple hypothesis, few answers. Front Neurol 2017;8:301

14. Wang J, Lin ZJ, Liu L, Xu HA, Shi YW, Yi YH, et al. Epilepsyassociated genes. Seizure 2017;44:11-20.

15. Tuchman R, Hirtz D, Mamounas LA. NINDS epilepsy and autism spectrum disorders workshop report. Am Acad Neurol 2013;81:1630-6.

16. Christensen J, Vestergaard M, Olsen J, Sidenius P. Validation of epilepsy diagnoses in the Danish national hospital register. Epilepsy Res 2007:75:162-70.

17. Silk TJ, Malpas CB, Beare R, Efron D, Anderson V, Hazell P, et al. A network analysis approach to ADHD symptoms: More than the sum of its parts. PLoS One 2019;14:e211053.

18. Davis NO, Kollins SH. Treatment for co-occuring attention deficit/ hyperactivity disorder and autism spectrum disorder. Neurotherapeutics 2012;9:518-30.

19. Besag F, Gobbi G, Caplan R, Sillanpaa M, Aldenkamp A, Dunn DW. Psychiatric and behavioural disorders in children with epilepsy (ILAE task force report): Epilepsy and ADHD. Epileptic Disord 2016;18:S8-15.

20. Kazemi M, Salehi M, Kheirollahi M. Down syndrome: Current status, challenges, and future perspectives. Int J Mol Cell Med 2016;5:125-33.

21. Dressler A, Perelli V, Bozza M, Bargagna S. The autistic phenotype 
in down syndrome: Differences in adaptive behaviour versus Down syndrome alone and autistic disorder alone. Funct Neurol 2011;26:151-8.

22. Eyk CL, Corbett MA, Gardner A, Bon BW, Broasbent JL, Harper K, et al. Analysis of 182 cerebral palsy transcriptomes points to dysregulation of trophic signalling pathways and overlap with autism. Transl Psychiatry 2018;8:88.

23. Sillanpaa M, Besag F, Aldenkamp A, Caplan R, Dunn DW, Gobbi G. Psychiatric and behavioural disorders in children with epilepsy (ILAE task force report): Epidemiology of psychiatric/behavioural disorder in children with epilepsy. Epileptic Disord 2016;18:S2-7.
24. Chandrakala E, Nagaraj K. Correlation between autistic endophenotypes and associated risk factors. Indian J Public Health Res Dev 2019;10:242-8.

25. Mehling MH, Tasse MJ. Severity of autism spectrum disorder: Current conceptualization, and transition to DSM-5. J Autism Dev Disord 2016;46:2000-16.

26. Vijayashankar S, Doss U, Damodaran LP, Arumugam G, Sridharan S. Analysis of salivary components to evaluate the pathogenesis of autism in children. Asian J Pharm Clin Res 2014;7:205-11

27. Besag FM. Epilepsy in patients with autism: Links, risks and treatment challenges. Neuropsych Dis Treat 2018;14:1-10. 